\title{
Medial Septum-Diagonal Band of Broca (MSDB) GABAergic Regulation of Hippocampal Acetylcholine Efflux Is Dependent on Cognitive Demands
}

\author{
Jessica J. Roland, ${ }^{2}$ Amanda L. Stewart, ${ }^{2}$ Kellie L. Janke, ${ }^{3}$ Matthew R. Gielow, ${ }^{4}$ John A. Kostek, ${ }^{2}$ Lisa M. Savage, ${ }^{5}$ \\ Richard J. Servatius, ${ }^{1,2,3}$ and Kevin C.H. Pang ${ }^{1,2,3}$ \\ ${ }^{1}$ Neurobehavioral Research Laboratory, Department of Veterans Affairs Medical Center-New Jersey Health Care System, East Orange, New Jersey 07018, \\ ${ }^{2}$ Stress and Motivated Behavior Institute and ${ }^{3}$ Graduate School of Biomedical Sciences, New Jersey Medical School-Rutgers University, Newark, New Jersey \\ 07103, ${ }^{4}$ Center for Molecular and Behavioral Neuroscience, Rutgers University, Newark, New Jersey 07102, and ${ }^{5}$ Behavioral Neuroscience Program, \\ Binghamton University, Binghamton, New York 13902
}

The septohippocampal pathway contains cholinergic, GABAergic, and glutamatergic projections and has an established role in learning, memory, and hippocampal theta rhythm. Both GABAergic and cholinergic neurons in the medial septum-diagonal band of Broca (MSDB) have been associated with spatial memory, but the relationship between the two neuronal populations is not fully understood. The present study investigated the effect of selective GABAergic MSDB lesions on hippocampal acetylcholine (ACh) efflux and spatial memory during tasks that varied in memory demand. Male Sprague Dawley rats were given GABAergic lesions of the MSDB using GAT1-saporin (GAT1-SAP) and examined on spontaneous exploration (Experiment 1) and non-matching to position without (NMTP; Experiment 2) and with a delay (DNMTP; Experiment 3), while concurrently using in vivo microdialysis to measure hippocampal ACh efflux. Intraseptal GAT1-SAP treatment did not alter baseline or behaviorally stimulated hippocampal ACh efflux or maze exploration (Experiment 1). Moreover, GAT1-SAP did not alter evoked hippocampal ACh efflux related to NMTP nor did it impair working memory in NMTP (Experiment 2). In contrast, both ACh efflux and performance in DNMTP were impaired by intraseptal GAT1-SAP. Thus, GABAergic MSDB neurons are important for spatial working memory and modulate hippocampal ACh efflux under conditions of high memory load. The relationship between the septohippocampal cholinergic and GABAergic systems and working memory will be discussed.

Key words: GAT1-saporin; hippocampus; learning; microdialysis; T-maze; working memory

\section{Introduction}

The medial septal-diagonal band of Broca (MSDB) is an important modulator of hippocampal function. The MSDB influences the hippocampus through projections from cholinergic, GABAergic, and glutamatergic neurons (Amaral and Kurz, 1985; Freund, 1989; Manseau et al., 2005). Lesions or inactivation of MSDB neurons impair hippocampal-dependent forms of learning and memory (Olton et al., 1979; Walker and Olton, 1984; Givens and Olton, 1990; Mizumori et al., 1990).

In addition to modulating hippocampal activity, MSDB GABAergic neurons influence other MSDB neurons. Both cholinergic and GABAergic MSDB neurons have GABAergic recep-

\footnotetext{
Received June 3, 2013; revised 0ct. 23, 2013; accepted Nov. 19, 2013.

Author contributions: J.J.R., R.J.S., and K.C.H.P. designed research; J.J.R., A.L.S., K.L.J., M.R.G., and J.A.K. performed research; L.M.S. contributed unpublished reagents/analytic tools; J.J.R. and K.C.H.P. analyzed data; J.J.R. and K.C.H.P. wrote the paper.

This work is supported by Biomedical Laboratory Research and Development Service of the Veterans' Affairs Office of Research and Development Award Number 101BX000132; National Institutes of Health grants T32NS051157, R01-NS44373, R01-NS054272; and the Stress and Motivated Behavior Institute.

The authors declare no competing financial interests.

Correspondence should be addressed to Kevin C. H. Pang, 385 Tremont Ave, Mailstop 129, East Orange, NJ 07018. E-mail: kevin.pang@va.gov.

DOI:10.1523/JNEUROSCI.2352-13.2014

Copyright $\odot 2014$ the authors $\quad 0270-6474 / 14 / 340506-09 \$ 15.00 / 0$
}

tors, receive input from GABAergic terminals (Leranth and Frotscher, 1989; Gaykema et al., 1991; Tóth et al., 1993; Gao et al., 1995) and display spontaneous IPSCs (Alreja et al., 2000). GABAergic agonists inhibit most MSDB neurons, while antagonists excite these cells (Lamour et al., 1984; Henderson and Jones, 2005; Manseau et al., 2005). In addition, hippocampal acetylcholine (ACh) efflux is decreased and increased by GABAergic agonists and antagonists, respectively (Gorman et al., 1994; Moor et al., 1998a, b). Furthermore, intraseptal GABAergic agonists impair hippocampal-dependent learning and memory (Chrobak et al., 1989; Givens and Olton, 1990, 1994; Durkin, 1992), while intraseptal GABAergic antagonists can facilitate learning and memory, but this is not always the case (Chrobak and Napier, 1991; Roland and Savage, 2009). These pharmacological studies cannot distinguish between influences from intrinsic GABAergic MSDB neurons and influences from extrinsic GABAergic afferents to the MSDB (Freund and Antal, 1988; Tóth and Freund, 1992; Tóth et al., 1993; Jinno and Kosaka, 2002).

In previous studies, we investigated the importance of intrinsic GABAergic MSDB neurons on learning and memory and hippocampal theta rhythm. Kainic acid or the immunotoxin GAT1saporin (GAT1-SAP) damaged GABAergic MSDB neurons while sparing cholinergic neurons (Pang et al., 2001, 2011). Spatial 
memory assessed by a delayed match to position task was impaired (Pang et al., 2011), whereas acquisition of spatial reference memory (win-stay on Morris water maze task) or spatial working memory (win-shift on radial maze) were spared (Pang et al., 2001). Incorrect responding on the delayed match to position task suggested an increase in proactive interference. GABAergic MSDB lesions also eliminated type II theta rhythm and reduced theta rhythm during locomotion (Yoder and Pang, 2005). Although these effects were attributed to damage of the GABAergic septohippocampal neurons, the effects could also be due to altering the function of non-GABAergic MSDB neurons such as cholinergic neurons (Pang et al., 2001, 2011).

The present study investigated the influence of GABAergic MSDB lesions on cholinergic MSDB function by assessing ACh efflux in the hippocampus. The importance of the MSDB cholinergic system may depend on the level of cognitive demand (Johnson et al., 2002; Hata et al., 2007; Easton et al., 2011); therefore, we measured ACh release in three procedures that differed in memory load. The results provide evidence that the intrinsic network of GABAergic MSDB neurons regulate hippocampal ACh release only during conditions of high memory load.

\section{Materials and Methods}

The effects of selective GABAergic MSDB lesions on hippocampal ACh efflux were examined during exploration and working memory tasks with varying demands. Selective GABAergic MSDB lesions were made using the toxin GAT1-SAP. Hippocampal ACh efflux was measured by in vivo microdialysis during spontaneous exploration (Experiment 1 ) and non-matching to position without (Experiment 2; NMTP) and with a delay (Experiment 3; DNMTP).

\section{Subjects}

Male Sprague Dawley rats, 3-4 months old (Charles River), were subjects of the study. All animals were maintained in a $12 \mathrm{~h}$ light/dark cycle, housed in standard laboratory cages (dimensions: $30 \times 45 \times 18 \mathrm{~cm}$ ), pair housed before surgery, and single housed after surgery. Animals were randomly assigned to receive a sham or GABAergic MSDB lesion using GAT1-SAP (Radley et al., 2009; Pang et al., 2011). After recovery from surgery and before microdialysis and behavioral testing, every animal was handled for $4 \mathrm{~d}, 10 \mathrm{~min}$ each day, and food restricted to $85 \%$ of their free-feeding weight. All animals in Experiments 2 and 3 were also acclimated to the maze and a sugared cereal for $2 \mathrm{~d}, 10 \mathrm{~min}$ each day. Behavioral and microdialysis sessions were performed during the light cycle. All procedures were conducted in accordance with the National Institutes of Health Guide for the Care and Use of Laboratory Animals and approved by the Institutional Animal Care and Use Committee of the Veterans Affairs Medical Center at East Orange, New Jersey.

\section{Stereotaxic surgery}

Subjects were anesthetized with a ketamine/xylazine mixture $(80 \mathrm{mg} /$ $\mathrm{ml}: 10 \mathrm{mg} / \mathrm{ml}$; i.p.) before stereotaxic surgery. With leveled skull, the needle of a Hamilton syringe ( $23 \mathrm{~g}$ ) was inserted into the MSDB to administer sterile PBS $(0.1 \mathrm{M})$ or GAT1-SAP (Advanced Targeting Systems; $325 \mathrm{ng} / \mu \mathrm{l}$ ), $0.5 \mu \mathrm{l}$ to the medial septum and $0.4 \mu \mathrm{l}$ to each diagonal band of Broca band at a rate of $0.1 \mu \mathrm{l} / \mathrm{min}$. Stereotaxic coordinates for the medial septum were as follows: $+0.6 \mathrm{~mm}$ anterior to bregma (AP), \pm 1.5 $\mathrm{mm}$ lateral to midline (ML), and $-6.6 \mathrm{~mm}$ below dura (DV). For the medial septal injections, the syringe was angled $15^{\circ}$ toward midline. The coordinates for the diagonal band of Broca were as follows: AP: +0.6 $\mathrm{mm}$; ML: $\pm 0.5 \mathrm{~mm}$; DV: $-7.8 \mathrm{~mm}$.

All animals were implanted with a microdialysis guide cannula (CMA/ 11; CMA) directed toward the ventral hippocampus. Whereas both dorsal and ventral hippocampus are important for spatial memory (de $\mathrm{Hoz}$ et al., 2003; Broadbent et al., 2004; Zhang et al., 2004), ACh efflux was measured from the ventral hippocampus because the ventral hippocampus receives more cholinergic innervation from the MSDB (Milner et al., 1983; Amaral and Kurz, 1985) and has a higher density of muscarinic receptors than the dorsal hippocampus (Garcia Ruiz et al., 1993). The coordinates for the microdialysis cannula were as follows: AP: $-5.1 \mathrm{~mm}$; ML: $\pm 5.0 \mathrm{~mm}$; DV: $-4.2 \mathrm{~mm}$. Placement of microdialysis probes into the left or right ventral hippocampus was counterbalanced for each lesion group. Acrylic cement and skull screws held the cannula in place. All rats received the analgesic Banamine $(0.1 \mathrm{mg} / \mathrm{kg}$, s.c.) immediately after surgery, and 24 and $48 \mathrm{~h}$ after surgery. Rats were allowed to recover from surgery for 10-12 d with ad libitum access to food and water before the start of any testing.

\section{Behavior}

Experiment 1. Previously, hippocampal ACh efflux was shown to increase during spontaneous exploration (Savage et al., 2003; Savage et al., 2007; Roland et al., 2008). In this study, the effects of intraseptal GAT1-SAP were investigated on exploration-induced hippocampal ACh efflux. A total of 16 rats $(\mathrm{PBS}=8$; GAT1-SAP $=8)$ were used. Spontaneous exploration in a plus maze occurred in a single day concurrently with microdialysis collection for hippocampal ACh efflux. The plus maze was constructed of wood painted black with four arms of equal distance (55 $\mathrm{cm}$ ); all arms were $10 \mathrm{~cm}$ wide and had sidewalls $12 \mathrm{~cm}$ high. The maze was elevated $80 \mathrm{~cm}$ from the floor and surrounded by various extra-maze cues (doors, tables, lighting fixtures, etc.).

Total arms and the sequence of arms entered by each rat were recorded. In addition to total arms, an exploration score was calculated using the following formula: number of times all four arms were entered in overlapping sets of five arm choices/(total number of arms entered 4) $\times 100$ (Ragozzino et al., 1996). The exploration score reflects the range of exploration. After traversal of the maze, animals were placed back in the holding cage for the collection of post maze samples (24 min).

Experiment 2. Hippocampal ACh efflux following intraseptal PBS or GAT1-SAP administration was assessed in two spatial working memory paradigms that differed in memory load (Experiments 2 and 3). Experiment 2 investigated a total of 24 rats $(\mathrm{PBS}=11$; GAT1-SAP $=13$ ) in an NMTP procedure with a short retention interval. The plus maze was identical to that described in Experiment 1. One stem of the plus maze was blocked to create a T-maze. The two goal arms were of equal distance $(55 \mathrm{~cm})$ and the start arm had a length of $45 \mathrm{~cm}$ (55 cm length arm with $10 \mathrm{~cm}$ blocked off for a start box). Manually operated wood block guillotine doors confined the rat to the start box between trials and forced rats to one goal arm during the forced run. The reinforcers were Froot Loops ( $1 / 2$ piece of cereal).

Each trial consisted of two parts that were $30 \mathrm{~s}$ in duration: the forced run and the choice run. On the forced run, one arm was blocked so the rat was "forced" to enter the other goal arm where it received a reinforcer. The choice run was identical to the forced run except both goal arms were available for entry. If the rat entered the goal arm opposite the one used during the forced run (non-match), it received a reinforcer and the choice was recorded as a correct response; the animal remained in this arm for the remainder of the $30 \mathrm{~s}$. If the rat entered the same goal arm used during the forced run, the rat was confined to the incorrect arm for the remainder of the $30 \mathrm{~s}$, no reinforcement was given, and the choice was recorded as an incorrect response. The goal arm on the forced run was predetermined using a random schedule that was different each day, but the same for all animals; the schedule consisted of six right and six left goal arms for a total of 12 trials each day. The delay between the forced run and the choice run was $\sim 0-5 \mathrm{~s}$ with a $60 \mathrm{~s}$ intertrial interval (ITI), making each trial $\sim 2 \mathrm{~min}$ and each training session $24 \mathrm{~min}$ in length. The sequence of forced arms used in Experiment 2 was used in Experiment 3.

Rats were trained on NMTP for 10 consecutive days. Given that hippocampal ACh efflux can differ over the course of NMTP training (Chang and Gold, 2003; Roland and Savage, 2007), rats were split into two groups; microdialysis for hippocampal ACh occurred on either day 2 (early: PBS $=6$, GAT1-SAP $=7$ ) or day 9 (late: PBS $=5$; GAT1-SAP $=$ 6) of NMTP training. All animals were trained on the NMTP task for $10 \mathrm{~d}$ regardless of when microdialysis occurred.

Experiment 3. Experiment 3 used a total of 31 rats (PBS = 15; GAT1$\mathrm{SAP}=16)$. All maze-training procedures were identical to Experiment 2, except animals in Experiment 3 were trained on a DNMTP task. The delay between the forced run and the choice run was $30 \mathrm{~s}$ with a $60 \mathrm{~s}$ ITI, 
making each trial $\sim 2 \mathrm{~min}$ and $30 \mathrm{~s}$ and each training session $30 \mathrm{~min}$ in length. As in Experiment 2, microdialysis was performed on one of two days during training: day 2 of training (early: $\mathrm{PBS}=8$, GAT1-SAP $=8$ ) or day 9 of training (late: $\mathrm{PBS}=7$; GAT1-SAP $=8$ ). All animals were trained on the DNMTP task for $10 \mathrm{~d}$ regardless of when microdialysis occurred.

\section{Microdialysis}

Before behavioral testing, subjects were transported to the testing room and placed in a holding cage [acrylic bucket $(30 \times 40 \mathrm{~cm}$, depth $35 \mathrm{~cm})$ with wood shavings at the bottom]. The holding cage was used for all non-maze microdialysis collections. The microdialysis probe (CMA/11; $3 \mathrm{~mm}$ ) was connected to a microinfusion system, inserted into the ventral hippocampus, and perfused continuously at a rate of $2 \mu \mathrm{l} / \mathrm{min}$ with artificial CSF (127.6 mM NaCl, $4 \mathrm{~mm} \mathrm{KCl}, 1.3 \mathrm{~mm} \mathrm{CaCl} 2$ dihydrate, 1.0 mu glucose, $0.9 \mathrm{~mm} \mathrm{MgCl}_{2}, 0.9 \mathrm{~mm} \mathrm{NaH}_{2} \mathrm{PO}_{4}$, and $2 \mathrm{mM} \mathrm{Na}_{2} \mathrm{HPO}_{4}, \mathrm{pH}$ 7.0) plus neostigmine bromide ( $500 \mathrm{~nm})$. Following an initial period of habituation to the holding cage (60 $\mathrm{min}$, no samples collected), dialysate samples $(12 \mu \mathrm{l})$ were collected every $6 \mathrm{~min}$ for the duration of the experiment. Samples were divided into three phases: baseline, maze, and post maze. In Experiments 1 and 2, each phase consisted of four 6 min samples, making each phase $24 \mathrm{~min}$. In Experiment 3, each phase consisted of five $6 \mathrm{~min}$ samples, making each phase $30 \mathrm{~min}$. After the last sample was collected, the microdialysis probe was placed into a solution containing $\mathrm{ACh}$ and choline (both $100 \mathrm{~nm}$ ) and the recovery rate was assessed. After collection, microdialysis samples were frozen at $-80^{\circ} \mathrm{C}$ for future analysis.

\section{HPLC}

Microdialysis samples were analyzed for ACh content using HPLC (Epison; BAS) along with an enzyme reactor. HPLC was conducted as previously described (Roland and Savage, 2007; Savage et al., 2007). The detection level was $\sim 10 \mathrm{fmol}$. ACh standards $(5 \mu \mathrm{l}$ of 20 and $100 \mathrm{~nm}$ $\mathrm{ACh}+\mathrm{Ch}$ ) were injected before and after samples to verify detection and probe stability. The level of ACh efflux (fmol) was calculated for each sample.

\section{Histology and immunocytochemistry}

Animals were perfused transcardially with $0.9 \%$ saline or $0.1 \mathrm{M}$ PBS followed by $10 \%$ formalin or $4 \%$ paraformaldehyde in $0.1 \mathrm{~m}$ phosphate buffer. Brains were removed and placed in formalin overnight followed by immersion in a $30 \%$ sucrose solution for $3-5 \mathrm{~d}$. Brains were then frozen and sectioned $(50 \mu \mathrm{m}$ ) with a sliding microtome (Sm 2000r; Leica Instruments). MSDB sections were evaluated for choline acetyltransferase (ChAT) and parvalbumin (PV) immunoreactivity (ir). Every fifth section, starting with the most rostral septal nuclei to the end of the diagonal band, was stained for ChAT-ir, resulting in four to five sections per animal with $200 \mu \mathrm{m}$ between each section. Adjacent sections were stained for PV-ir. Immunocytochemistry procedures were conducted as previously described (Pang et al., 2011). Briefly, sections were incubated in goat anti-ChAT IgG (1:500 dilution; Millipore Bioscience Research Reagents) or mouse anti-PV IgG (1:1000; Sigma Immunochemicals) followed by the appropriate biotinylated secondary antibody (1:200; Jackson ImmunoResearch).

For rats used in the microdialysis studies, the location of the microdialysis probe was confirmed using cresyl violet staining. All animals included in the final data analysis had accurate MSDB lesions and hippocampal cannula placement.

To assess damage of GABAergic hippocamposeptal neurons, 23 rats (Charles River) received MS injections of GAT1-SAP (325 ng/ $\mu \mathrm{l}, 0.5 \mu \mathrm{l}$; $N=12$ ) or PBS injections ( $0.1 \mathrm{M}$ sterile PBS; $0.5 \mu \mathrm{l} ; N=11$ ) as described above. These rats were not used in the microdialysis studies. Following GAT1-SAP injections, the retrograde tracer Fluoro-Gold (FG; $0.2 \mu \mathrm{l}, 2 \%$ in $0.1 \mathrm{M}$ acetate buffer) was administered into the MS using the same coordinates as for GAT1-SAP. Rats were euthanized 2 weeks following surgery, and brains were prepared for immunocytochemistry as described above. The ventral hippocampus was stained for somatostatin-ir (SS-ir) or calbindin D-28k (CB), as the majority of GABAergic hippocamposeptal neurons are SS-ir or CB-ir (Zappone and Sloviter, 2001; Jinno and Kosaka, 2002). Every fifth section between $\sim 4.30$ and $6.48 \mathrm{~mm}$ posterior to bregma was selected, resulting in nine to ten sections per animal with $200 \mu \mathrm{m}$ between each section. Sections were incubated in rat anti-SS (1:100; Millipore) or mouse anti-CB (1:2000; Sigma-Aldrich) followed by Cy3-donkey anti-rat IgG or Cy3-donkey anti-mouse IgG (1:100; Jackson ImmunoResearch).

\section{Unbiased stereology}

Three rats in each treatment condition from each of the experiments were randomly selected to assess the damage caused by GAT1-SAP $(\mathrm{PBS}=9$; GAT1-SAP $=9$ ). Estimates of ChAT-ir and PV-ir cells were made in the MSDB with the experimenter blind to the treatment of the rat. Stereology was performed using the optical fractionator method (West, 1993) with the program Stereo Investigator (v.9.10.5; MicroBrightField) on a microscope with an $x$-, $y$-, and $z$-axis motorized stage (Bio Point 30; Ludl Electronic Products). The counting frame and grid size were $75 \times 100 \mu \mathrm{m}$ and $150 \times 200 \mu \mathrm{m}$, respectively, with a guard zone of $5 \mu \mathrm{m}$.

To assess damage to hippocamposeptal GABAergic neurons, unbiased stereological estimation for single-labeled FG and double labeled FG + SS-ir (FG/SS-ir) or FG + CB-ir (FG/CB-ir) cells was performed using the optical fractionator method (Stereo Investigator v.9.10.5; MicroBrightField) on a Leica DM4000B microscope with an $x$-, $y$-, and $z$-axis motorized stage (Applied Scientific Instrumentation). The counting frame and grid size were $90 \times 90 \mu \mathrm{m}$ and $360 \times 360 \mu \mathrm{m}$, respectively, with a guard zone of $5 \mu \mathrm{m}$.

\section{Data analysis}

All statistical analyses were performed with SPSS for Windows (version 12.0.1) with $\alpha=0.05$. For cell counts, data were expressed as mean \pm SEM, and independent sample $t$ tests were performed to identify group differences. For microdialysis, average baseline ACh efflux (fmol) was expressed as mean \pm SEM. For Experiment 1 , ACh efflux (fmol) was analyzed using a mixed design ANOVA with treatment as a betweensubjects factor and phase and sample as within-subject factors. For Experiments 2 and 3, ACh efflux (fmol) was analyzed using a mixed design ANOVA with treatment group and time of microdialysis (i.e., early or late in training) as between-subjects factors and phase and sample as within-subject factors. When appropriate, post hocs were conducted using an $F$ test. For behavior, data are expressed as mean \pm SEM. For spontaneous exploration, group differences in exploration score and total arms entered were assessed using independent sample $t$ tests. For NMTP and DNMTP training, group differences in choice accuracy ( percentage correct) were assessed using a mixed design ANOVA with a treatment group as a between-subjects factor and session as a withinsubject factor. Planned comparisons were conducted within each group to assess overall learning.

\section{Results}

\section{Histology}

To determine the selectivity of the GAT1-SAP toxin in the MSDB, we estimated ChAT- and PV-ir neurons (Fig. 1b). GAT1-SAP reduced the number of PV-ir MSDB neurons by 57\% (PBS: $3627 \pm 422$; GAT1-SAP: $\left.1556 \pm 285 ; t_{(16)}=4.06 ; p=0.001\right)$. In contrast, intraseptal GAT1-SAP did not reduce ChAT-ir cells (PBS: $7098 \pm 1005$; GAT1-SAP: $5851 \pm 965 ; t_{(16)}=0.89$; $p=0.38)$.

The ability of intraseptal GAT1-SAP to damage GABAergic neurons projecting into the MSDB was investigated. The number of FG-labeled cells was used to assess changes in the total number of hippocamposeptal neurons. Double-labeled FG/SS-ir and FG/ CB-ir cells represented different populations of GABAergic hippocamposeptal neurons (Jinno and Kosaka, 2002). Estimates of FG, FG/SS-ir, and FG/CB-ir neurons were determined in the ventral hippocampus (Fig. 1a). PBS- and GAT1-SAP-treated rats had $51,828 \pm 9514$ and 49,180 \pm 6594 single-labeled FG cells, respectively. These estimates were not significantly different $t_{(21)}=$ $0.23 ; p=0.82)$. PBS- and GAT1-SAP-treated rats had $4746 \pm$ 
a
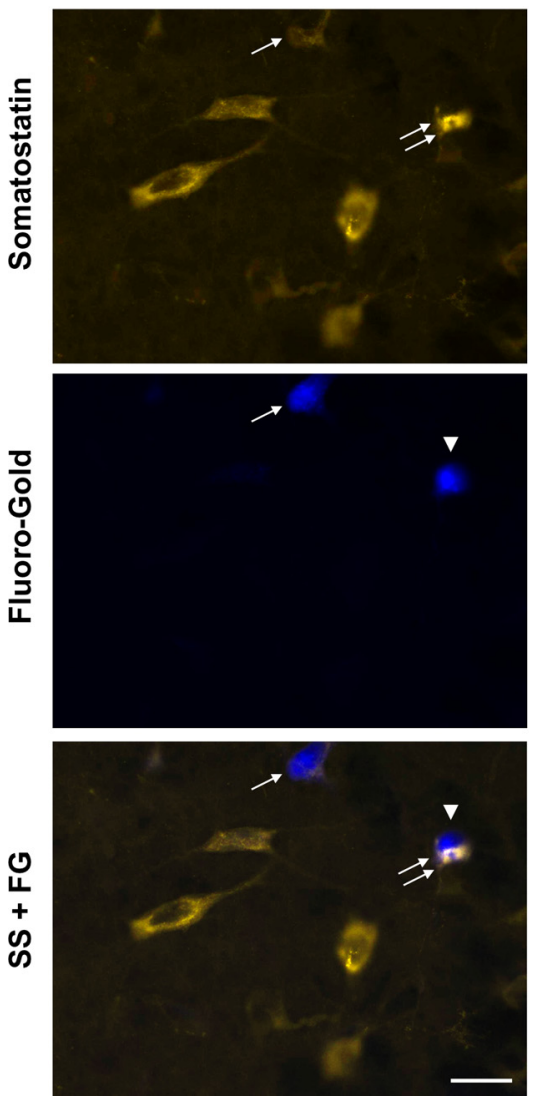

b
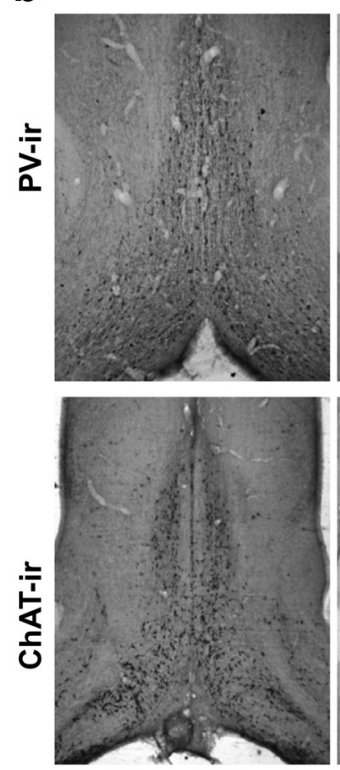

C

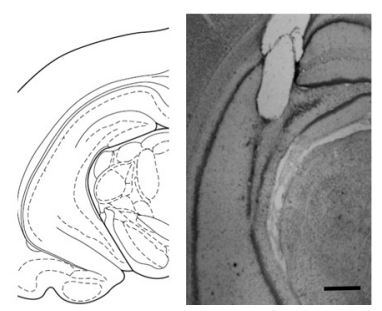

Figure 1. a, Photomicrographs of hippocampal cells containing SS-ir (top), hippocamposeptal neurons containing FG (middle), and the two images overlaid (bottom). The single arrow shows a SS-ir hippocamposeptal neuron (FG- and SS-ir). The arrowhead points to a hippocamposeptal neuron that is not SS-ir and the double arrows show a SS-ir hippocampal neuron without $\mathrm{FG}$; these two cells are located close together but are not double labeled. Other SS-ir hippocampal neurons that do not contain $\mathrm{FG}$ are observed in the top panel. Scale bar, $20 \mu \mathrm{m}$. $\boldsymbol{b}$, Photomicrographs of the MSDB in both PBS- and GAT1-SAP-treated animals. Immunoreactivity for PV and ChAT was used to visualize GABAergic and cholinergic MSDB neurons, respectively. Scale bar (right bottom), $1 \mathrm{~mm}$. c, A brain atlas representation and a photomicrograph of a cresyl violetstained section showing probe placement for the hippocampal microdialysis cannula. Scale bar, $1 \mathrm{~mm}$.

1138 and $3913 \pm 516$ double-labeled FG/SS-ir cells, respectively. Group differences were not significant $\left(t_{(7)}=0.61 ; p=0.56\right)$. Double-labeled FG/CB-ir cells in PBS- and GAT1-SAP-treated rats were $4127 \pm 1601$ and $5906 \pm 1281$ cells, respectively, and these differences were not significant $\left(t_{(12)}=0.88 ; p=0.40\right)$. Thus, intraseptal GAT1-SAP does not significantly alter the number of hippocamposeptal GABAergic neurons.

\section{Experiment 1}

Hippocampal ACh efflux

A representative microdialysis cannula placement in the ventral hippocampus is shown in Figure 1c. Exploration induced a rise in hippocampal ACh efflux above baseline efflux, but intraseptal GAT1-SAP did not alter this increase. Baseline ACh efflux did not differ between treatment groups $\left(F_{(1,14)}=1.06 ; p=0.32\right.$; Fig. 2$)$. Exploration increased ACh efflux in both groups, as demonstrated by a significant main effect for microdialysis phase $\left(F_{(2,28)}=\right.$ $12.81 ; p<0.0001)$ and a phase $\times$ sample interaction $\left(F_{(6,84)}=\right.$ $2.37 ; p=0.036$ ). GAT1-SAP administered into the MSDB did not alter exploration-induced ACh efflux, as neither the main effect of treatment $\left(F_{(1,14)}=1.07 ; p=0.32\right)$ nor interactions involving treatment (all $p s>0.34$ ) was significant (Fig. 2). Thus, intraseptal GAT1-SAP did not alter basal or exploration-induced hippocampal efflux.

Behavioral performance

Intraseptal GAT1-SAP did not alter exploration on the plus maze. Both PBSand GAT1-SAP-treated animals did not differ in maze exploration, as demonstrated by the lack of significant differences in exploration scores (PBS: $41.1 \pm$ 9.95; GAT1-SAP: $34.3 \pm 10.99 ; t_{(14)}=$ $0.46 ; p=0.65)$ or total number of arms entered (PBS: $17.4 \pm 1.22$; GAT1-SAP: $\left.18.1 \pm 4.72 ; t_{(14)}=0.15 ; p=0.88\right)$.

\section{Experiment 2}

One PBS and two GAT1-SAP animals were not included in the final analysis due to misplaced microdialysis cannulae or incomplete damage of GABAergic MSDB neurons (final subject totals: $\mathrm{PBS}=10$, early $=5$, and late $=5$; GAT1-SAP $=11$, early $=6$, and late $=5$ ).

\section{Hippocampal ACh efflux}

Intraseptal GAT1-SAP did not alter hippocampal ACh efflux during NMTP (Fig. 3a). As in Experiment 1, basal hippocampal ACh efflux was not changed by damage to GABAergic MSDB neurons $\left(F_{(1,19)}=1.35 ; p=0.26\right)$. Overall hippocampal ACh efflux increased during performance of NMTP, as evidenced by a significant main effect of phase $\left(F_{(2,34)}=\right.$ 14.37; $p<0.0001)$ and a phase $\times$ sample interaction $\left(F_{(6,102)}=9.72 ; p<0.0001\right)$. However, intraseptal GAT1-SAP did not modify hippocampal ACh efflux; neither main effect of treatment group $\left(F_{(1,17)}=\right.$ $1.51 ; p=0.24)$ nor interaction of treatment with other factors (phase $\times$ treatment: $F_{(2,34)}=1.09 ; p=0.35$; sample $\times$ treatment $\left.F_{(3,51)}=0.19 ; p=0.90\right)$ was significant. The day on which microdialysis was performed did not influence ACh efflux; neither main effect of day of microdialysis nor any interaction involving day was significant, all $p s>$ 0.135 . Therefore, performing the NMTP procedure increased hippocampal ACh efflux in both treatment groups similarly.

\section{Behavioral performance}

Intraseptal GAT1-SAP did not alter NMTP performance (Fig. $3 b)$. Performance was measured by choice accuracy; choice accuracy started at $\sim 65 \%$ and increased to $\sim 85 \%$ by the end of training (10 sessions). The increase in choice accuracy with training was significant (main effect of session: $F_{(9,171)}=8.49 ; p<$ 0.0001). GAT1-SAP treatment, though, did not significantly alter NMTP performance (main effect of treatment group: $F_{(1,19)}=$ 2.23; $p=0.15$; session $\times$ treatment group: $F_{(9,171)}=0.75 ; p=$ 0.66). Therefore, intraseptal GAT1-SAP treatment did not impair the ability of animals to perform the NMTP task.

\section{Experiment 3}

Four PBS and six GAT1-SAP animals were not included in the final analysis due to misplaced microdialysis cannulae or incomplete damage of GABAergic MSDB neurons (final subject totals: $\mathrm{PBS}=11$, early $=6$, and late $=5 ; \mathrm{GAT} 1-\mathrm{SAP}=10$, early $=5$, and late $=5$ ). 


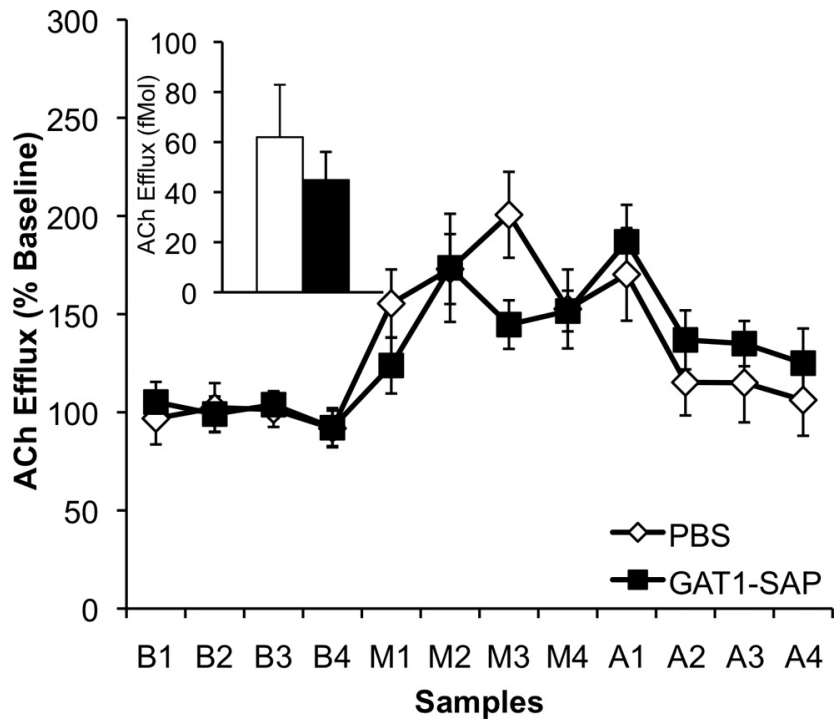

Figure 2. Profile of hippocampal ACh efflux (percentage of baseline average; mean $\pm S E M$ ) in PBS- and GAT1-SAP-treated animals; inset displays average basal hippocampal ACh efflux $(\mathrm{fmol})$ in both groups. Both groups had an increase in exploration-evoked hippocampal ACh efflux ( $M$ samples) above their own baselines (B samples). However, MSDB GAT1-SAP treatment did not change basal or exploration-evoked hippocampal ACh efflux (A samples $=$ postmaze phase).

\section{Hippocampal ACh efflux}

Hippocampal ACh efflux during performance of DNMTP was reduced following intraseptal GAT1-SAP (Fig. 4a). Similar to Experiments 1 and 2, baseline hippocampal ACh efflux was not altered in GAT1-SAP-treated animals during this experiment $\left(F_{(1,19)}=0.07 ; p=0.79\right)$. Hippocampal ACh efflux increased while rats performed in DNMTP, as revealed by a significant main effect of phase $\left(F_{(2,34)}=12.67 ; p<0.0001\right)$ and a phase $\times$ sample interaction $\left(F_{(8,136)}=4.01 ; p<0.0001\right)$. However, GAT1-SAP reduced the hippocampal ACh efflux observed during DNMTP, as demonstrated by a phase $\times$ sample $\times$ treatment group interaction $\left(F_{(8,36)}=2.87 ; p=.006\right)$. These results demonstrate that, in contrast to NMTP, evoked hippocampal ACh efflux was reduced during the more memory demanding task of DNMTP following intraseptal GAT1-SAP. Although both groups of animals had a significant rise in their respective hippocampal ACh efflux during the DNMTP phase, the rise of GAT1-SAPtreated animals was blunted when compared with PBS-treated animals ( $\sim 77 \%$ of PBS-treated rats). The day on which microdialysis was performed did not influence ACh efflux, as neither main effect of day nor any interaction involving day was significant, all $p s>0.54$.

\section{Behavioral performance}

Intraseptal GAT1-SAP impaired performance in DNMTP (Fig. $4 b)$. Overall, animals performed better with more training sessions (main effect of session: $F_{(9,171)}=4.85 ; p<0.0001$ ). In contrast to NMTP, GAT1-SAP-treated rats were impaired in choice accuracy compared with PBS animals in DNMTP (main effect of treatment group: $F_{(1,19)}=23.01 ; p<0.0001$, but no treatment $\times$ session interaction: $\left.F_{(9,171)}=0.54 ; p=0.84\right)$. Therefore, intraseptal GAT1-SAP treatment significantly impaired choice accuracy in the DNMTP task.

\section{Comparison of basal ACh efflux in Experiments 1-3}

Differences in basal efflux were observed between experiments; the main effect of experiment was significant, $F_{(2,52)}=3.24, p=$ a
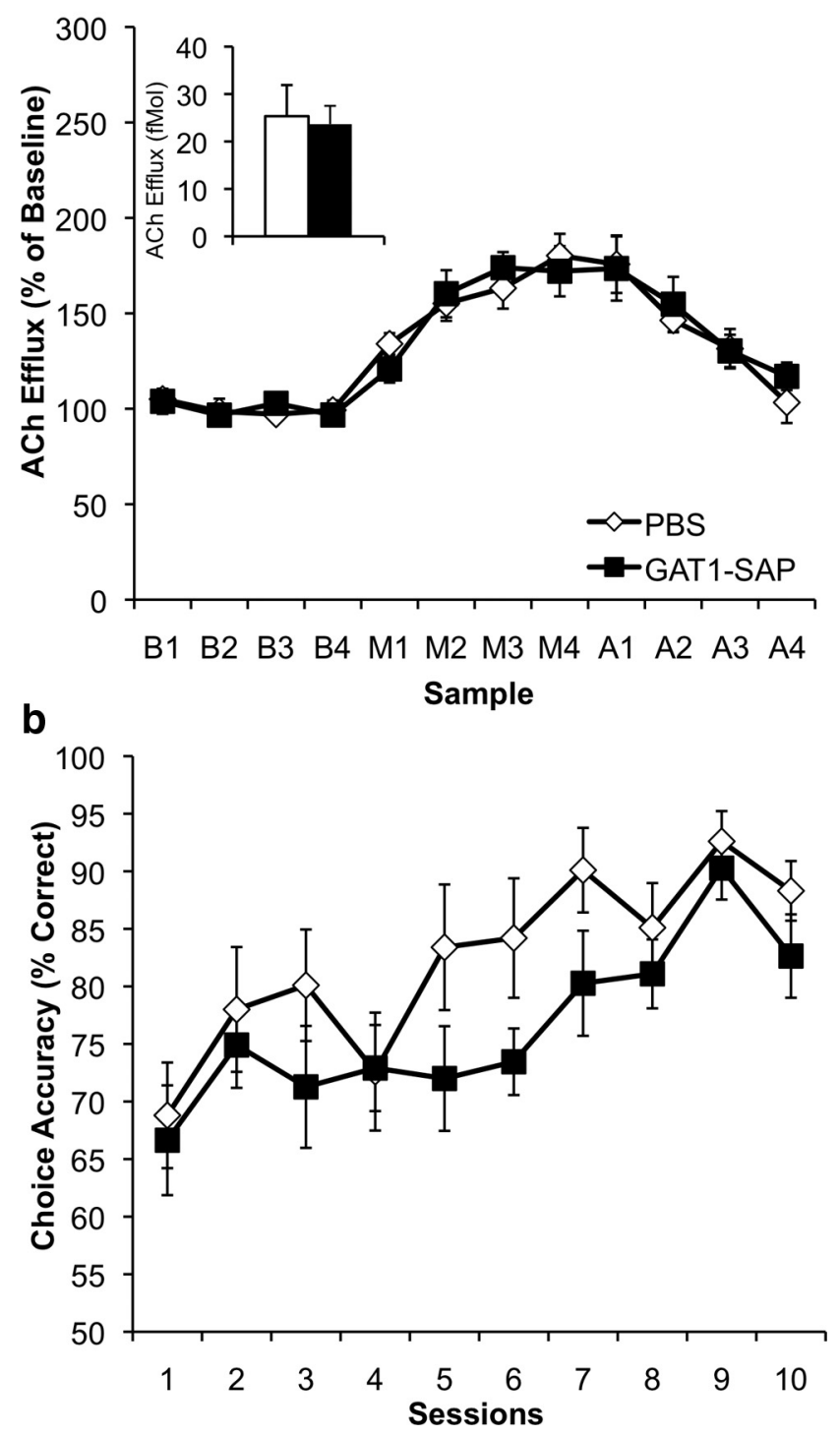

Figure 3. $\quad \boldsymbol{a}$, Profile of hippocampal ACh efflux (percentage of baseline average; mean \pm SEM) in PBS- and GAT1-SAP-treated animals; inset displays average basal hippocampal ACh efflux (fmol) in both groups. Both groups showed an increase in maze-evoked hippocampal ACh efflux (M samples) above their own baseline (B samples). However, MSDB GAT1-SAP treatment did not change basal or maze-evoked hippocampal ACh efflux (A samples = post-maze phase). $\boldsymbol{b}$, Behavioral data (mean \pm SEM) over 10 consecutive days of NMTP training in both PBS- and MSDB GAT1-SAP-treated animals. Intraseptal GAT1-SAP did not alter NMTP performance.

0.047. Post hoc analysis showed that basal ACh efflux differed only between the spontaneous exploration and the NMTP studies. Due to the nature of the studies, the maze room was novel for spontaneous exploration and familiar for NMTP. Novelty enhances ACh efflux (Acquas et al., 1996; Giovannini et al., 2001) and may explain the differences in basal ACh efflux between the two experiments.

\section{Discussion}

The current study investigated the importance of intrinsic GABAergic MSDB neurons on cholinergic function by monitoring hippocampal ACh efflux during three different behavioral and mnemonic conditions. The major findings are that destruction of GABAergic MSDB neurons reduced evoked hippocampal ACh efflux and impaired performance during an NMTP proce- 

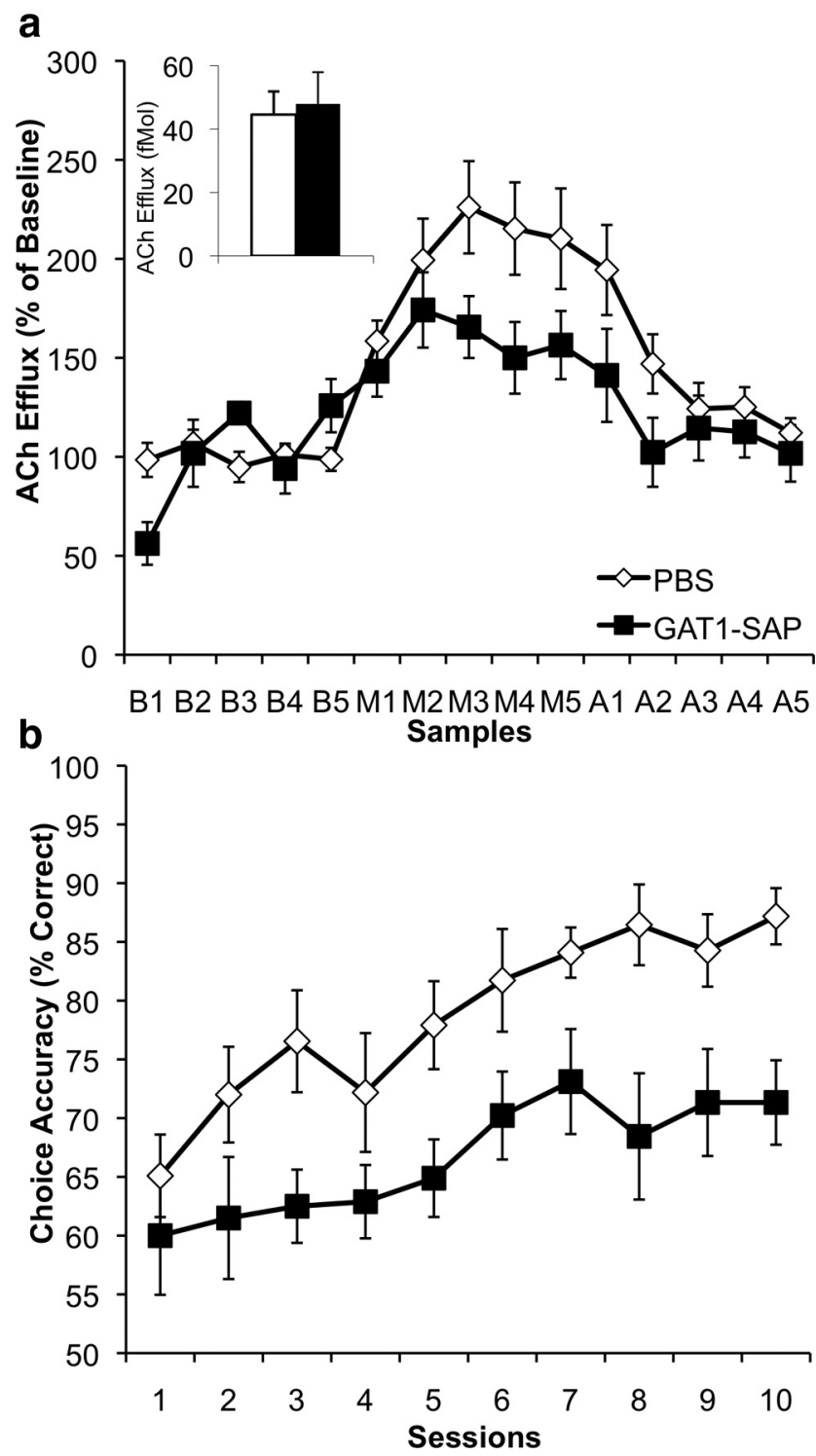

Figure 4. $\quad \boldsymbol{a}$, Profile of hippocampal ACh efflux (percentage of baseline average; mean \pm SEM) in PBS- and GAT1-SAP-treated animals; inset displays average basal hippocampal ACh efflux (fmol) in both groups. MSDB GAT1-SAP treatment did not change basal hippocampal ACh efflux. Both sham and GAT1-SAP groups had an increase in maze-evoked hippocampal ACh efflux (M samples) above their own baseline (B samples). In addition, MSDB GAT1-SAP treatment reduced maze-evoked hippocampal $A C h$ efflux as compared with PBS animals (A samples $=$ post-maze phase). $\boldsymbol{b}$, Behavioral data (mean \pm SEM) over 10 consecutive days of DNMTP training in both PBS- and MSDB GAT1-SAP-treated animals. Intraseptal GAT-SAP impaired DNMTP performance compared with PBS animals. GAT1-SAP animals did not significantly increase their choice accuracy over $10 \mathrm{~d}$ of training.

dure with a long, but not a short, retention interval. In addition, GABAergic MSDB neurons did not influence baseline hippocampal ACh efflux or ACh efflux evoked by exploration. The results suggest that intrinsic GABAergic MSDB neurons may critically modulate cholinergic MSDB function during conditions of increased cognitive load.

Intraseptal GAT1-SAP treatment reduced PV-ir MSDB neurons without significantly altering the number of cholinergic neurons, similar to previous studies (Pang et al., 2011; Köppen et al., 2013). Additionally, the number of hippocamposeptal cells was not altered following intraseptal GAT1-SAP. Moreover, loss of specific GABAergic hippocamposeptal populations (SS-ir and CBir) was not significantly reduced following intraseptal GAT1-SAP, although subtle losses may remain undetected. The ineffectiveness of GAT1-SAP in damaging GABAergic neurons following administration into the terminal field is consistent with a previous study (Radley et al., 2009), and contrasts with the effects of a related toxin 192-IgG saporin (Ohtake et al., 1997).

Intraseptal GAT1-SAP treatment did not alter basal hippocampal ACh efflux. This finding was unexpected because intraseptal administration of GABA antagonists increased hippocampal ACh efflux (Moor et al., 1998a, b; Roland and Savage, 2009). Moreover, local administration of GABA antagonists increased the activity of the large majority of MSDB neurons, although the neurochemical phenotype of the neurons was not identified (Lamour et al., 1984; Henderson and Jones, 2005; Manseau et al., 2005). Finally, cholinergic MSDB neurons express spontaneous IPSCs (Alreja et al., 2000). All of these results support the idea that hippocampal $\mathrm{ACh}$ release is under tonic GABAergic inhibition in the MSDB. Therefore, enhanced hippocampal ACh efflux following GABAergic MSDB lesions was predicted. This was not found in the present study. Instead, basal hippocampal ACh efflux was not affected by intraseptal GAT1-SAP.

Intraseptal GAT1-SAP did not alter exploration-evoked hippocampal ACh efflux. Exploration of novel environments and spontaneous alternation enhance hippocampal ACh efflux (Day et al., 1991; Roland and Savage, 2007; Savage et al., 2007) and similar findings were observed in the present study. Furthermore, the amplitude of evoked hippocampal ACh efflux correlates with the amount of exploration on a plus maze (Chang and Gold, 2003). Consistent with this finding, the amount of exploration did not differ between GAT1-SAP rats and sham rats, and neither did the amplitude of exploration-evoked ACh efflux.

Several factors may contribute to the ineffectiveness of intraseptal GAT1-SAP treatment on basal and exploration-induced ACh efflux. First, behavior and ACh efflux were assessed weeks after damage of GABAergic neurons. Compensatory changes in both GABAergic and cholinergic systems may have occurred, resulting in a re-balancing of the systems. Second, PV-ir neurons were reduced by $57 \%$ following GAT1-SAP administration, this reduction is less than that observed in our previous study (Pang et al., 2011). Remaining GABAergic neurons may provide sufficient inhibition to keep basal and exploration-induced ACh efflux from increasing. Finally, the feedback circuit between the MSDB and hippocampus may dampen cholinergic activity following loss of GABAergic MSDB neurons. By destroying GABAergic septohippocampal projection cells, GAT1-SAP would reduce disinhibition of hippocampal pyramidal cells, as GABAergic septohippocampal neurons project primarily to hippocampal interneurons (Freund and Antal, 1988; Freund, 1989). Decreased activity of hippocampal pyramidal cells would decrease excitatory tone on GABAergic hippocamposeptal neurons that primarily project to GABAergic MSDB neurons (Tóth and Freund, 1992; Tóth et al., 1993). This effect would also reduce disinhibition in the MSDB and effectively reduce cholinergic neuronal activity.

To more clearly delineate the importance of GABAergic MSDB neurons in working memory and its associated hippocampal ACh efflux, the effect of intraseptal GAT1-SAP was investigated using a NMTP procedure with two retention intervals. GAT1-SAP impaired DNMTP (30 s retention interval) but not NMTP ( 0 s retention interval) performance. Given that the general procedures for NMTP and DNMTP are identical except for retention interval, the differential results suggest that GABAergic MSDB neurons are particularly important during situations 
of increasing memory load. These results are similar to complete fimbria-fornix lesions, which produce delay-dependent impairments in delayed match- and non-match-to-sample tasks (Dunnett, 1985; Tonkiss et al., 1990; Weiner et al., 1998; Bussey et al., 2000). Fimbria-fornix transections damage GABAergic and cholinergic projections between the MSDB and hippocampus. However, cholinergic MSDB damage with 192-IgG saporin did not impair spatial memory in a delay-dependent manner (McMahan et al., 1997), further highlighting the importance of noncholinergic MSDB neurons.

Memory impairment was paralleled by a delay-dependent reduction of evoked hippocampal ACh efflux. Hippocampal ACh efflux increased specifically during the maze phase of both NMTP and DNMTP, similar to previous studies (Chang and Gold, 2003; Roland and Savage, 2007). GAT1-SAP did not reduce the amount of ACh efflux during NMTP as compared with sham rats. Interestingly, the amount of evoked efflux during NMTP was similar in amplitude to that evoked by exploration, and neither was affected by intraseptal GAT1-SAP treatment.

In contrast to NMTP, ACh efflux during DNMTP was less for GAT1-SAP-treated rats than for sham rats. In sham rats, hippocampal ACh efflux increased to a greater extent during DNMTP than during NMTP. In GAT1-SAP-treated rats, the enhanced ACh efflux seen in shams during DNMTP was not observed. That is, ACh efflux was similar during NMTP and DNMTP in rats treated with intraseptal GAT1-SAP. Reduced ACh efflux in GAT1-SAP rats during DNMTP may be related to reduced reinforcement received by GAT1-SAP rats compared with sham rats. Food reinforcement is associated with increased hippocampal ACh efflux (Iso et al., 1999). It is unlikely that our results are due to differences in food reinforcement. First, ACh efflux was similar during spontaneous exploration and NMTP, even though rats received reinforcement during NMTP but not spontaneous exploration. Second, hippocampal ACh efflux in sham rats was less during NMTP than DNMTP, even though rats received more reinforcement in NMTP than in DNMTP. Finally, hippocampal ACh efflux in GAT1-SAP rats was similar in DNMTP and NMTP, even though they received more reinforcements during NMTP than during DNMTP. Thus, hippocampal ACh efflux was not correlated with food reinforcement in the present study. In summary, our findings demonstrate two important points. First, hippocampal ACh efflux increases as memory load increases. Second, GABAergic MSDB neurons are important in enhancing hippocampal ACh efflux selectively during conditions of increasing memory load. Our results also add to a sparse literature demonstrating a relation between amount of hippocampal ACh efflux and task difficulty (Hata et al., 2007) and implicates GABAergic MSDB neurons in modulating ACh release as a function of task demand.

Selective damage of GABAergic MSDB neurons impaired performance in a spatial learning task with high proactive interference, but did not alter performance in a similar task with low interference (Pang et al., 2001, 2011). In the present study, the impairment is most simply explained by an increase in retention interval. Thus, GABAergic MSDB neurons are important in conditions with high cognitive demand, including those with high proactive interference or long retention intervals.

GABAergic MSDB neurons could facilitate hippocampal ACh efflux during DNMTP by (1) inhibiting hippocampal interneurons that inhibit ACh release presynaptically (Tóth and Freund, 1992; Tóth et al., 1993; Moor et al., 1998a; Giorgetti et al., 2000; Seto et al., 2002), (2) causing disinhibition of cholinergic MSDB neurons through GABAergic hippocamposeptal neurons (Freund and Antal, 1988; Freund, 1989; Woolf, 1991; Tóth et al., 1993; Hasselmo, 2005), or (3) inducing hippocampal theta rhythm (Lee et al., 1994; Yoder and Pang, 2005; Hangya et al., 2009). Hippocampal ACh efflux is positively correlated with hippocampal theta rhythm (Marrosu et al., 1995; Monmaur et al., 1997). Conditions of high cognitive load are associated with more theta rhythm and synchronization of theta activity between different brain regions (Weiss et al., 2000; Bischof and Boulanger, 2003; Choi et al., 2010), allowing dynamic networks to form (Klimesch, 1996; Cashdollar et al., 2009) and potentially enhancing excitatory input to cholinergic MSDB neurons and increasing hippocampal ACh efflux.

Enhanced hippocampal ACh release may provide a mechanism for increasing attention to the working memory problem. Cortical ACh has an important role in attention to sensory cues (Robbins et al., 1989; Muir et al., 1992; Parikh et al., 2007; Hasselmo and Sarter, 2011; Sarter and Paolone, 2011). Hippocampal ACh may have a similar role in enhancing attention to items in the working memory buffer. Conditions in which items in the memory buffer have high signal-to-noise ratios would require little attention and little need for hippocampal ACh. High proactive interference could increase noise, whereas long retention intervals could decrease the signal. In either case, attention and hippocampal ACh may be necessary to efficiently select the proper item in working memory.

Finally, it is unlikely that the reduction of hippocampal ACh efflux during DNMTP is solely responsible for the impaired performance because selective cholinergic MSDB lesions using 192IgG saporin produce little to no impairment in spatial working memory tasks (Berger-Sweeney et al., 1994; Pang et al., 2001; Kirby and Rawlins, 2003; Dwyer et al., 2007). More likely, MSDB GABAergic and cholinergic neurons work together. In some conditions (low working memory demand), impaired performance is only seen when both systems are damaged (Pang et al., 2001). In other situations (high working memory demand), selective damage of GABAergic but not cholinergic MSDB neurons is sufficient to impair performance (Dwyer et al., 2007; present study); however, these are conditions in which GABAergic MSDB lesions reduce hippocampal ACh efflux. Thus, GABAergic and cholinergic MSDB neurons appear to function as redundant systems in which either alone is sufficient to support working memory. Further support for a redundant model comes from the finding that memory impairment caused by inactivation of both MSDB populations with muscimol can be reversed by enhancing just the cholinergic system via intrahippocampal physostigmine (Degroot and Parent, 2000).

In summary, intraseptal GAT1-SAP treatment did not alter baseline or exploration-evoked hippocampal ACh efflux. Animals with a GAT1-SAP MSDB lesion were impaired on an NMTP task only when there was a $30 \mathrm{~s}$ delay and this impairment paralleled a blunted rise in hippocampal ACh efflux. Sham animals learned both the NMTP and the DNMTP task and displayed a greater increase in hippocampal ACh efflux during the DNMTP as compared with the NMTP task. These findings suggest that the septohippocampal pathway is necessary when the memory load is increased.

\section{References}

Acquas E, Wilson C, Fibiger HC (1996) Conditioned and unconditioned stimuli increase frontal cortical and hippocampal acetylcholine release: effects of novelty, habituation, and fear. J Neurosci 16:3089-3096. Medline

Alreja M, Shanabrough M, Liu W, Leranth C (2000) Opioids suppress IPSCs in neurons of the rat medial septum/diagonal band of Broca: involvement 
of m-opioid receptors and septohippocampal GABAergic neurons. J Neurosci 20:1179-1189. Medline

Amaral DG, Kurz J (1985) An analysis of the origins of the cholinergic and noncholinergic septal projections to the hippocampal formation of the rat. J Comp Neurol 240:37-59. CrossRef Medline

Berger-Sweeney J, Heckers S, Mesulam MM, Wiley RG, Lappi DA, Sharma M (1994) Differential effects on spatial navigation of immunotoxininduced cholinergic lesions of the medial septal area and nucleus basalis magnocellularis. J Neurosci 14:4507-4519. Medline

Bischof WF, Boulanger P (2003) Spatial navigation in virtual reality environments: an EEG analysis. CyberPsychol Behav 6:487-495. CrossRef Medline

Broadbent NJ, Squire LR, Clark RE (2004) Spatial memory, recognition memory, and the hippocampus. Proc Natl Acad Sci U S A 101:1451514520. CrossRef Medline

Bussey TJ, Duck J, Muir JL, Aggleton JP (2000) Distinct patterns of behavioural impairments resulting from fornix transection or neurotoxic lesions of the perirhinal and postrhinal cortices in the rat. Behav Brain Res 111:187-202. CrossRef Medline

Cashdollar N, Malecki U, Rugg-Gunn FJ, Duncan JS, Lavie N, Duzel E (2009) Hippocampus-dependent and -independent theta-networks of active maintenance. Proc Natl Acad Sci U S A 106:20493-20498. CrossRef Medline

Chang Q, Gold PE (2003) Switching memory systems during learning: changes in patterns of brain acetylcholine release in the hippocampus and striatum in rats. J Neurosci 23:3001-3005. Medline

Choi JW, Jung KY, Kim CH, Kim KH (2010) Changes in gamma- and thetaband phase synchronization patterns due to the difficulty of auditory oddball task. Neurosci Lett 468:156-160. CrossRef Medline

Chrobak JJ, Napier TC (1991) Intraseptal administration of bicuculline produces working memory impairments in the rat. Behav Neural Biol 55:247-254. CrossRef Medline

Chrobak JJ, Stackman RW, Walsh TJ (1989) Intraseptal administration of muscimol produced dose-dependent memory impairments in the rat. Behav Neural Biol 52:357-369. CrossRef Medline

Day J, Damsma G, Fibiger HC (1991) Cholinergic activity in the rat hippocampus, cortex and striatum correlates with locomotor activity: an in vivo microdialysis study. Pharmacol Biochem Behav 38:723-729. CrossRef Medline

Degroot A, Parent MB (2000) Increasing acetylcholine levels in the hippocampus or entorhinal cortex reverses the impairing effects of septal GABA receptor activation on spontaneous alternation. Learn Mem 7:293-302. CrossRef Medline

de Hoz L, Knox J, Morris RG (2003) Longitudinal axis of the hippocampus: both septal and temporal poles of the hippocampus support water maze spatial learning depending on the training protocol. Hippocampus 13: 587-603. CrossRef Medline

Dunnett SB (1985) Comparative effects of cholinergic drugs and lesions of nucleus basalis or fimbria-fornix on delayed matching in rats. Psychopharmacology 87:357-363. CrossRef Medline

Durkin TP (1992) GABAergic mediation of indirect transsynaptic control over basal and spatial memory testing-induced activation of septohippocampal cholinergic activity in mice. Behav Brain Res 50:155-165. CrossRef Medline

Dwyer TA, Servatius RJ, Pang KC (2007) Noncholinergic lesions of the medial septum impair sequential learning of different spatial locations. J Neurosci 27:299-303. CrossRef Medline

Easton A, Fitchett AE, Eacott MJ, Baxter MG (2011) Medial septal cholinergic neurons are necessary for context-place memory but not episodiclike memory. Hippocampus 21:1021-1027. Medline

Freund TF (1989) GABAergic septohippocampal neurons contain parvalbumin. Brain Res 478:375-381. CrossRef Medline

Freund TF, Antal M (1988) GABA-containing neurons in the septum control inhibitory interneurons in the hippocampus. Nature 336:170-173. CrossRef Medline

Gao B, Hornung JP, Fritschy JM (1995) Identification of distinct GABA-a receptor subtypes in cholinergic and parvalbumin-positive neurons of the rat and marmoset medial septum diagonal band complex. Neuroscience 65:101-117. CrossRef Medline

Garcia Ruiz AJ, Zambelli M, La Porta C, Ladinsky H, Consolo S (1993) Differences between the rat doral and ventral hippocampus in muscarinic receptors agonist binding and interaction with phospholipase C. Eur J Pharmacol 244:125-131. CrossRef Medline

Gaykema RP, Gaál G, Traber J, Hersh LB, Luiten PG (1991) The basal forebrain cholinergic system: efferent and afferent connectivity and longterm effects of lesions. Acta Psychiatr Scand Suppl 366:14-26. Medline

Giorgetti M, Bacciottini L, Giovannini MG, Colivicchi MA, Goldfarb J, Blandina P (2000) Local GABAergic modulation of acetylcholine release from the cortex of freely moving rats. Eur J Neurosci 12:1941-1948. CrossRef Medline

Giovannini MG, Rakovska A, Benton RS, Pazzagli M, Bianchi L, Pepeu G (2001) Effects of novelty and habituation on acetylcholine, GABA, and glutamate release from the frontal cortex and hippocampus of freely moving rats. Neuroscience 106:43-53. CrossRef Medline

Givens BS, Olton DS (1990) Cholinergic and GABAergic modulation of medial septal area: effect on working memory. Behav Neurosci 104:849-855. CrossRef Medline

Givens B, Olton DS (1994) Local modulation of basal forebrain: effects on working and reference memory. J Neurosci 14:3578-3587. Medline

Gorman LK, Pang K, Frick KM, Givens B, Olton DS (1994) Acetylcholine release in the hippocampus: effects of cholinergic and GABAergic compounds in the medial septal area. Neurosci Lett 166:199-202. CrossRef Medline

Hangya B, Borhegyi Z, Szilágyi N, Freund TF, Varga V (2009) GABAergic neurons of the medial septum lead the hippocampal network during theta activity. J Neurosci 29:8094-8102. CrossRef Medline

Hasselmo ME (2005) What is the function of hippocampal theta rhythm?Linking behavioral data to phasic properties of field potential and unit recording data. Hippocampus 15:936-949. CrossRef Medline

Hasselmo ME, Sarter M (2011) Modes and models of forebrain cholinergic neuromodulation of cognition. Neuropsychopharmacology 36:52-73. CrossRef Medline

Hata T, Kumai K, Okaichi H (2007) Hippocampal acetylcholine efflux increases during negative patterning and elemental discrimination in rats. Neurosci Lett 418:127-132. CrossRef Medline

Henderson Z, Jones GA (2005) GABA-b receptors in the medial septum/ diagonal band slice from $16-25$ day rat. Neuroscience 132:789-800. CrossRef Medline

Iso H, Ueki A, Shinjo H, Miwa C, Morita Y (1999) Reinforcement enhances hippocampal acetylcholine release in rats: an in vivo microdialysis study. Behav Brain Res 101:207-213. CrossRef Medline

Jinno S, Kosaka T (2002) Immunocytochemical characterization of hippocamposeptal projecting GABAergic nonprincipal neurons in the mouse brain: a retrograde labeling study. Brain Res 945:219-231. CrossRef Medline

Johnson DA, Zambon NJ, Gibbs RB (2002) Selective lesion of cholinergic neurons in the medial septum by 192 IgG-saporin impairs learning in a delayed matching to position T-maze paradigm. Brain Res 943:132-141. CrossRef Medline

Klimesch W (1996) Memory processes, brain oscillations and EEG synchronization. Int J Psychophysiol 24:61-100. CrossRef Medline

Kirby BP, Rawlins JN (2003) The role of the septo-hippocampal cholinergic projection in T-maze rewarded alternation. Behav Brain Res 143:41-48. CrossRef Medline

Köppen JR, Winter SS, Stuebing SL, Cheatwood JL, Wallace DG (2013) Infusion of GAT1-saporin into the medial septum/vertical limb of the diagonal band disrupts self-movement cue processing and spares mnemonic function. Brain Struct Funct 218:1099-1144. Medline

Lamour Y, Dutar P, Jobert A (1984) Septo-hippocampal and other medial septum-diagonal band neurons: electrophysiological and pharmacological properties. Brain Res 309:227-239. CrossRef Medline

Lee MG, Chrobak JJ, Sik A, Wiley RG, Buzsáki G (1994) Hippocampal theta activity following selective lesion of the septal cholinergic system. Neuroscience 62:1033-1047. CrossRef Medline

Leranth C, Frotscher M (1989) Organization of the septal region in the rat brain: cholinergic-GABAergic interconnections and the termination of hippocampo-septal fiber. J Comp Neurol 289:304-314. CrossRef Medline

Manseau F, Danik M, Williams S (2005) A functional glutamatergic neurone network in the medial septum and diagonal band area. J Physiol 566:865-884. CrossRef Medline

Marrosu F, Portas C, Mascia MS, Casu MA, Fà M, Giagheddu M, Imperato A, Gessa GL (1995) Microdialysis measurement of cortical and hippocam- 
pal acetylcholine release during sleep-wake cycle in freely moving cats. Brain Res 671:329-332. CrossRef Medline

McMahan RW, Sobel TJ, Baxter MG (1997) Selective immunolesions of hippocampal cholinergic input fail to impair spatial working memory. Hippocampus 7:130-136. CrossRef Medline

Milner TA, Loy R, Amaral DG (1983) An anatomical study of the development of the septo-hippocampal projection in the rat. Brain Res 284:343371. Medline

Mizumori SJ, Perez GM, Alvarado MC, Barnes CA, McNaughton BL (1990) Reversible inactivation of the medial septum differentially affects two forms of learning in rats. Brain Res 528:12-20. CrossRef Medline

Monmaur P, Collet A, Puma C, Frankel-Kohn L, Sharif A (1997) Relations between acetylcholine release and electrophysiological characteristics of theta rhythm: a microdialysis study in the urethane-anesthetized rat hippocampus. Brain Res Bull 42:141-146. CrossRef Medline

Moor E, DeBoer P, Westerink BH (1998a) GABA receptors and benzodiazepine binding sites modulate hippocampal acetylcholine release in vivo. Eur J Pharmacol 359:119-126. CrossRef Medline

Moor E, Schirm E, Jacsó J, Westerink BHC (1998b) Involvement of medial septal glutamate and GABA receptors in behaviour-induced acetylcholine release in the hippocampus: a dual probe microdialysis study. Brain Res 789:1-8. CrossRef Medline

Muir JL, Dunnett SB, Robbins TW, Everitt BJ (1992) Attentional functions of the forebrain cholinergic systems: effects of intraventricular hemicholinium, physostigmine, basal forebrain lesions and intracortical grafts on a multiple-choice serial reaction time task. Exp Brain Res 89:611-622. Medline

Ohtake T, Heckers S, Wiley RG, Lappi DA, Mesulam MM, Geula C (1997) Retrograde degeneration and colchicine protection of basal forebrain cholinergic neurons following hippocampal injections of an immunotoxin against the P75 nerve growth factor receptor. Neuroscience 78:123133. CrossRef Medline

Olton DS, Becker JT, Handelmann GE (1979) Hippocampus, space and memory. Behav Brain Sci 2:313-365. CrossRef

Pang KC, Nocera R, Secor AJ, Yoder RM (2001) GABAergic septohippocampal neurons are not necessary for spatial memory. Hippocampus 11:814-827. CrossRef Medline

Pang KC, Jiao X, Sinha S, Beck KD, Servatius RJ (2011) Damage of GABAergic neurons in the medial septum impairs spatial working memory and extinction of active avoidance: effects on proactive interference. Hippocampus 21:835-846. Medline

Parikh V, Kozak R, Martinez V, Sarter M (2007) Prefrontal acetylcholine release controls cue detection on multiple timescales. Neuron 56:141154. CrossRef Medline

Radley JJ, Gosselink KL, Sawchenko PE (2009) A discrete GABAergic relay mediates medial prefrontal cortical inhibition of the neuroendocrine stress response. J Neurosci 29:7330-7340. CrossRef Medline

Ragozzino ME, Unick KE, Gold PE (1996) Hippocampal acetylcholine release during memory testing in rats: augmentation by glucose. Proc Natl Acad Sci U S A 93:4693-4698. CrossRef Medline

Robbins TW, Everitt BJ, Marston HM, Wilkinson J, Jones GH, Page KJ (1989) Comparative effects of ibotenic acid- and quisqualic acidinduced lesions of the substantia innominata on attentional function in the rat: further implications for the role of the cholinergic neurons of the nucleus basalis in cognitive processes. Behav Brain Res 35:221-240. CrossRef Medline

Roland JJ, Savage LM (2007) Blunted hippocampal, but not striatal, acetyl- choline efflux parallels learning impairment in diencephalic-lesioned rats. Neurobiol Learn Mem 87:123-132. CrossRef Medline

Roland JJ, Savage LM (2009) Blocking GABA-A receptors in the medial septum enhances hippocampal acetylcholine release and behavior in a rat model of diencephalic amnesia. Pharmacol Biochem Behav 92:480-487. CrossRef Medline

Roland JJ, Mark K, Vetreno RP, Savage LM (2008) Increasing hippocampal acetylcholine levels enhances behavioral performance in an animal model of diencephalic amnesia. Brain Res 1234:116-127. CrossRef Medline

Sarter M, Paolone G (2011) Deficits in attentional control: cholinergic mechanisms and circuitry-based treatment approaches. Behav Neurosci 125:825-835. CrossRef Medline

Savage LM, Chang Q, Gold PE (2003) Diencephalic damage decreases hippocampal acetylcholine release during spontaneous alternation testing. Learn Mem 10:242-246. CrossRef Medline

Savage LM, Roland J, Klintsova A (2007) Selective septohippocampal-but not forebrain amygdalar-cholinergic dysfunction in diencephalic amnesia. Brain Res 1139:210-219. CrossRef Medline

Seto D, Zheng WH, McNicoll A, Collier B, Quirion R, Kar S (2002) Insulinlike growth factor-I inhibits endogenous acetylcholine release from the rat hippocampal formation: possible involvement of GABA in mediating the effects. Neuroscience 115:603-612. CrossRef Medline

Tonkiss J, Feldon J, Rawlins JN (1990) Section of the descending columns of the fornix produces delay- and interference-dependent working memory deficits. Behav Brain Res 36:113-126. CrossRef Medline

Tóth K, Freund TF (1992) Calbindin D28k-containing nonpyramidal cells in the rat hippocampus: their immunoreactivity for GABA and projection to the medial septum. Neuroscience 49:793-805. CrossRef Medline

Tóth K, Borhegyi Z, Freund TF (1993) Postsynaptic targets of GABAergic hippocampal neurons in the medial septum-diagonal band of broca complex. J Neurosci 13:3712-3724. Medline

Walker JA, Olton DS (1984) Fimbria-fornix lesions impair spatial working memory but not cognitive mapping. Behav Neurosci 98:226-242. CrossRef Medline

Weiner I, Feldon J, Tarrasch R, Hairston I, Joel D (1998) Fimbria-fornix cut affects spontaneous activity, two-way avoidance and delayed non matching to sample, but not latent inhibition. Behav Brain Res 96:59-70. CrossRef Medline

Weiss S, Müller HM, Rappelsberger P (2000) Theta synchronization predicts efficient memory encoding of concrete and abstract nouns. Neuroreport 11:2357-2361. CrossRef Medline

West MJ (1993) New stereological methods for counting neurons. Neurobiol Aging 14:275-285. CrossRef Medline

Woolf NJ (1991) Cholinergic systems in mammalian brain and spinal cord. Prog Neurobiol 37:475-524. CrossRef Medline

Yoder RM, Pang KC (2005) Involvement of GABAergic and cholinergic medial septal neurons in hippocampal theta rhythm. Hippocampus 15:381392. CrossRef Medline

Zappone CA, Sloviter RS (2001) Commissurally projecting inhibitory interneurons of the rat hippocampal dentate gyrus: a colocalization study of neuronal markers and retrograde tracer Fluoro-Gold. J Comp Neurol 441:324-344. Medline

Zhang WN, Pothuizen HH, Feldon J, Rawlins JN (2004) Dissociation of function within the hippocampus: effects of dorsal, ventral and complete excitotoxic hippocampal lesions on spatial navigation. Neuroscience 127: 289-300. CrossRef Medline 